\title{
UTOPIAS AND DySTOPIAS AS MODELS OF SOCIAL TECHNOLOGY
}

\author{
IVAN FERREIRA DA CUNHA
}

\begin{abstract}
This paper presents some proposals for social science advanced by Otto Neurath, focusing on scientific utopianism. Neurath suggests that social scientists should formulate ideals of social arrangements in utopian style, aiming at discussing scientific proposals with a community. Utopias are deemed as models of social science, in the sense proposed by Nancy Cartwright. This view is contrasted with the claim that scientism might lead to dystopian consequences in social planning, drawn from Aldous Huxley's fiction and from Paul Feyerabend's philosophy of science. Thus, social science displays a unusual feature: sometimes a model has to be called off, in spite of its perfect functioning, because it brings about unwanted consequences. In the planning of a free democratic society, this ambiguity of utopia and dystopia is highly desirable, for it stimulates essential debates. Social science, therefore, is to be regarded from a plural and fallibilist standpoint.
\end{abstract}

Keywords: Neurath; Feyerabend; nomological machines; philosophy of science; science fiction.

\section{Introduction}

In the first decades of the 20th century, two apparently opposite feelings coexisted. On the one hand, the enthusiasm about social science, which came with the realization that the powerful methods and techniques of science were finally reaching the domain of social facts and human relations, bringing the hope for a scientifically planned society, marked by justice and happiness. On the other hand, the fear of the rising totalitarian governments, which threatened civil liberties and individual freedom with violence and obscurantism. In the science-fiction novel Brave New World, Aldous Huxley shows that the two feelings might not be so contradictory, as he visualizes the risk that scientism, a blind faith in science, brings forth a different form of totalitarianism. Those two feelings are conjoined as well in the works of Otto Neurath, as he proposes that social science adopts a creative stance, such that utopias are to be considered the object of social technology; Neurath advances a plural, fallibilist, and democratic conception of social science as a weapon against totalitarianism. By the end of the century, however, the hope for a scientifically planned society had become closer to the fear of a foggy totalitarianism. This can be noticed in the works of Paul Feyerabend. He argues that the increasing presence of science in our lives is a risk to a free democratic society.

Principia 19(3): 363-377 (2015).

Published by NEL — Epistemology and Logic Research Group, Federal University of Santa Catarina (UFSC), Brazil. 
This paper is going to discuss Neurath's proposals in regard to that recent framework in philosophy of science. In that context, Neurath's utopias stand out as offering an optimistic way for science to deal with social problems. This paper is going to compare Neurath's conception of utopias to the notion of scientific models, taken from Nancy Cartwright's works. Understanding utopias as models of social science, in a plural and fallibilist framework, may help us resist the threat of a totalitarian scientism.

\section{The Dystopia of Scientism}

Imagine that the great powers of the world, upon acknowledging a global crisis, come into an agreement and decide to fund a huge scientific research program to plan the whole of society. Suppose that, instead of aiming at the maintenance of the power structure, this enterprise aims at warranting happiness for everybody. So the research starts by discovering what that means. The answers obtained are not hard to figure out: people want to be a useful part of society; and to be rewarded for that role with plenty of everything they like, without frustrations and disappointments. Scientists realize that the best way to guarantee such a happiness is to break up some biological constraints and some cultural traditions. This new society where everybody is happy all the time requires biological engineering: all human reproduction is carried through in laboratory, marriage and family are abolished, as well as religion. This grants sexual freedom and the end of all the frustration and psychic distress caused by the expectations of beloved ones and social groups. Everybody is biologically programmed to perform their role in society. Besides that, education, which becomes a wholly societal matter, provides all sorts of psychological conditioning to warrant that everyone fits in and, at the same time, enjoys all the happiness society offers. Any frustration or boredom that eventually transpires can be dealt with by means of carefully administered drugs and hormone therapy, which, being designed to act upon engineered organisms, have few side effects. With such a controlled population, environmental balance is reached, our planet is no longer in danger. Transportation and communication means are developed as to provide comfort; diseases, crime, and war are completely eradicated.

Notwithstanding the obvious advantages of such a social arrangement, some people might feel uneasy with the great deal of freedom that is lost. However, we must bear in mind that there is no absolute freedom whatsoever, we are always under some kind of restraint. For example, in countries where there is no governmental censorship on the press, the free expression of opinions is usually restricted by economic reasons; when one can choose one's own job or career, such a choice is made among the possibilities that life presents, besides the individual aptitudes one hap-

Principia 19(3): 363-377 (2015). 
pens to have; and even those who have everything sometimes complain of loneliness, boredom, and unhappiness. Arguments for a society like that may be as numerous and reasonable as the arguments against it. In the book Brave New World, Aldous Huxley imagines that most of the world population was somehow convinced by such arguments and adhered to such a society (Huxley 2006 [1932]).

In Huxley's story, some inhospitable, barren, and peripheral parts of the world remained (almost) untouched; people in those places kept living as it is currently done - or, at least, as people do in third-world countries. Human life and culture is secured in reservations at those places in forms which are regarded by the characters in the book as wild and uncivilized. These reservations seem to serve as genetic and cultural bank, as well as adventurous touristic destinations. Huxley's story develops when one of the so-called savages from the reservations is brought to the civilized world. This causes disruption as the different life forms are confronted - the main characters will never again be the same, will not be able to enjoy the happiness of civilization in the same way anymore (Huxley 2006 [1932]).

The aim of Brave New World, as Huxley explains in Brave New World Revisited, a later non-literary text, is to raise awareness about the fact that humankind is being taken towards a subtle kind of totalitarianism - one which does not use torture, censorship, and violence to obtain control, but entertainment, propaganda, and science. Huxley's proposals for avoiding such a tendency go in the political and educational field: he says that we should "educate ourselves and our children for freedom and self-government" (Huxley 2006 [1958], p.109). The problem, he points out, is in considering society to be more important than the individual, so that keeping up with social values becomes more important than one's own freedom of will. His considerations on education are towards preventing the praise of social values over individual ones (Huxley 2006 [1958]).

\section{Philosophy of Science, Education, and Politics}

Huxley's discussions do not enter much the field of philosophy of science, our theme in this text. But Paul Feyerabend presents philosophical reflections about science, by means of which he comes to considerations about education and democracy which are similar to Huxley's.

Feyerabend argues that "the wide divergence of individuals, schools, historical periods, entire sciences makes it extremely difficult to identify comprehensive principles either of method, or of fact" in order to establish a univocal concept of science. "The word 'science", he continues, "may be a single word - but there is no single entity that corresponds to that word" (Feyerabend 1993, p.238). He notices that there is nothing distinctive about science, nothing that cannot be found in other activities.

Principia 19(3): 363-377 (2015). 
Hence, he sees no reason to consider science as a privileged point of view, life form, or type of knowledge: science has no superior method that grants its rationality and objectivity, or its capacity to get increasingly closer to the truth about the world. In his words, the idea that science presents a "unique set of standards that has always led to success and will always lead to success is nothing but a chimera". Thus, Feyerabend says, "the theoretical authority of science is much smaller than it is supposed to be. Its social authority, on the other hand, has by now become so overpowering that political interference is necessary to restore a balanced development" (Feyerabend 1993, p.160).

The political interference for which Feyerabend argues is that science should not be used by governments or big enterprises to reach their special goals without critical reasoning; therefore, people should be educated to develop questioning thought regarding science. He criticizes a form of scientism, the belief that science is a superior sort of knowledge and that it constitutes the sole alternative for a rational way of life. Feyerabend argues that there cannot be a single notion of rationality, which would be universal and stable, valid for every rational being everywhere. Such an idea, he claims, "is as unrealistic as the idea of a universal and stable measuring instrument that measures any magnitude, no matter what the circumstances" (Feyerabend 1982 [1978], p.98).

People should be taught a diverse variety of rationality standards, in order to master the best instruments humankind has developed. Education, Feyerabend points out, "should prepare citizens to choose between the standards, or to find their way in a society that contains groups committed to various standards, but it must under no condition bend their minds so that they conform to the standards of one particular group" (Feyerabend 1993, p.161).

A free society, argues Feyerabend, grants a space for science, but also to those activities which are considered as non-scientific. It would be possible for such "nonscientific ideologies, practices, theories, traditions" to develop, to improve themselves, and so they "can become powerful rivals and can reveal major shortcomings of science if only they are given a fair chance to compete. It is the task of the institutions of a free society to give them such a fair chance" (Feyerabend 1982 [1978], p.103). Therefore, even science might be improved with this plural flourishing of human activities. Feyerabend gives the example of Chinese medicine, which, for many decades was relegated to the condition of non-scientific practice. In such a condition, it could not be the subject of any serious research. The situation changed in the 1950's, when, for political and nationalistic reasons, it was enforced by the ruling party of China (Feyerabend 1982 [1978], p.102-3). Half a century later, some techniques of Chinese medicine are being incorporated into Western medicine - that is, some of those non-scientific practices have proven to be effective even in scientific standards.

Principia 19(3): 363-377 (2015). 
Given this variety of standards, Feyerabend proposes that science, in all its diversity, should not cling to some kind of singularity - to one correct method, to one pattern of rationality, to one concept of objectivity. The philosophical portraits of science should, likewise, display such a diversity. Science should be, and should be viewed as, plural, as the variety of activities, institutions, ideas, theories, claims, world-views, life forms, etc., that it actually is. Feyerabend calls for pluralism: if humankind presents a broad variety of standards of rationality, many of them can be found within the scope of science, then the rules of any given standard of rationality should not be taken so seriously, for there are other standards to be followed and even to be discovered. This plurality is already present in the practice of science, as Feyerabend sees in his historical studies. It just needs to become widely recognized. Such a recognition is a step towards a free, democratic society.

\section{Neurath's Social Technology}

In face of Huxley's dystopia and Feyerabend's considerations, one might feel inclined to reject any possibility of using science to plan society, opposing the development of researches that can be characterized as social engineering. This, however, might lead to even worse situations, as the individuals who were enlightened by such ideas would withdraw from the debate, and social planning might be taken over by unscrupulous technocrats. Huxley and Feyerabend propose political and educational transformations to warrant free democracy. This plan can be reinforced by developing a more democratic, less technocratic, social science, such as the one proposed by Otto Neurath. ${ }^{1}$

A commonly recognized aspect of social science is the uniqueness of the social situation. The object of study of social science is very complex, it contains many variables, many different aspects which are impossible to be reproduced. It is even difficult for two social situations to be alike in many respects. Hence, experiments in social science are almost impossible - and it is hard even to constitute a reasonable experiential background to guide future researches. The complexity of social situations requires their study to be carried through from as many perspectives as possible. Social science is necessarily a plural enterprise, composed not only of the various so called social sciences, but also of the many approaches in each of them. ${ }^{2}$

These two related aspects of social situations, uniqueness and complexity, and their significance for social science were taken into account by Neurath in his Foundations of the Social Sciences (1970 [1944]). He proposes that we call aggregate [Ballung] the basic object of social science, instead of the usual expressions 'social fact' or 'human relations', which might evoke the misleading idea of something atomic that cannot be further analyzed. ${ }^{3}$ Aggregates, or Ballungen, can be experienced in 
everyday life and described by means of everyday language, ${ }^{4}$ and, therefore, social science must start "with a full lump of irregularities and indistinctness, as our daily speech offers it. Afterwards we may find some regularities in it and relate some items even to a calculus with all its exactness and its formulae. (...) Social scientists need this richness and indistinctness" (Neurath 1970 [1944], p.18). A social situation, in this account, is a Ballung that can be studied by many disciplines, such as sociology, anthropology, geography, political science, psychology, economy, in the diverse theoretical frameworks within them; and also by disciplines such as biology, chemistry, geology and climatology, which also constitute and influence the situation. ${ }^{5}$

Since social situations are so unstable, such that "even a small variation in the initial state may bring about a tremendous difference in the state of the whole aggregation in question" (Neurath 1970 [1944], p.28), it is a hard task to establish a reliable set of previous experiences. Without such a background, it is problematic for social scientists to gather uniformities and devise generalizations which would allow predictions. Moreover, Neurath points out, predictions, when made, become a part of the Ballung itself, because they may influence the decisions of the social groups. It is difficult to imagine how a unique and complex object, like a social situation, is going to behave, especially when it might change its behavior according to what is expected and predicted of it.

Difficult, but not impossible. Interventions in social situations must take into account that such situations are unique and complex; a work of social technology ${ }^{6}$ must be planned in a relatively large scale, regarding as many as possible of the diverse elements that constitute the Ballung at issue. The plans for social intervention are called 'utopias' by Neurath, following the literary tradition of imagining social arrangements. He calls for creativity in social technology, for the development of new, unimagined social inventions that may help communities deal with their problems. Assuming that the instability of social situations poses a limitation for social engineering to predict and invent, Neurath argues that "this limitation of engineering is perhaps not due to the infinite number of possibilities, as some people assume, but to our limits in finding and handling possible solutions" (Neurath 1970 [1944], p.31). Creativity, therefore, must be put to work, more utopias are needed, since they are efforts of creating new social arrangements, which might contribute to the improvement of society. "Scientific utopianism", says Neurath, "seems to be a fair scientific enterprise, and we may deal with its procedures seriously" (Neurath 1970 [1944], p.31; also see Neurath 1979 [1919]; Neurath 2004 [1920-1]; and Nemeth 1991).

The most famous aspect of Neurath's philosophy of science is fallibilism: according to him, even observation reports must be taken as revisable. And social technology constructions, the utopias, just like every scientific construction, are fallible, are not perfect once-and-for-all solutions to any problem. Utopias are to be regarded as plans to guide a process of permanent improvement of society - a process that is also not 
perfect, that is marked by trial and error, and by constant debates in which many people from different backgrounds with diverse aims take part. Such a process is never carried through with the best means and materials we can imagine, but only with the best we can find and provide. Having a plan to guide the process is important, but we must expect that such a plan changes all the time, just as the needs and wishes of the people who put it into practice. Besides, we are not able to leave society and rebuild it out of nothing: the old achievements are our starting point. Our survival in the world, which can be improved by the scientific enterprise, is a plural and fallible endeavor - and science cannot be different. These aspects of Neurath's philosophy are featured in his well-known ship analogy. The last version of this analogy was presented in The Foundations of the Social Sciences, the text we are discussing here: ${ }^{7}$

\begin{abstract}
Imagine sailors who, far out at sea, transform the shape of their clumsy vessel from a more circular to a more fishlike one. They make use of some drifting timber, besides the timber of the old structure, to modify the skeleton and the hull of their vessel. But they cannot put the ship in dock in order to start from scratch. During their work they stay in the old structure and deal with heavy gales and thundering waves. In transforming their ship they take care that dangerous leakages do not occur. A new ship grows out of the old one, step by step - and while they are still building, the sailors may already be thinking of a new structure, and they will not always agree with one another. The whole business will go on in a way we cannot even anticipate today (Neurath 1970 [1944], p.47).
\end{abstract}

In another paper, I seek to show Neurath's utopianism as an urge for scientists to create and consider in a more serious manner the utopias of literary artists. ${ }^{8}$ In that paper, I compare Neurath's view of utopias as fallible, plural, and in constant reconstruction to two literary texts by H. G. Wells, A Modern Utopia and Men Like Gods (Wells 2005 [1905], and Wells 1923, respectively). The former, A Modern Utopia, for example, is marked by a dialogue between the narrator, optimistic about the utopian world, and his friend, who sees that society as a terrible dystopia. Wells explains that "the Modern Utopia must be not static, but kinetic, must shape not as a permanent state but as a hopeful stage leading to a long ascent of stages" (Wells 2005 [1905], p.11). Wells shows societies which are not perfect, as in traditional utopias, but are in a constant process of improvement. The communities described in those books have the capacity of reshaping themselves as problems appear. This capacity is the utopia, the ideal to be striven for, in Wells's view, and it can be compared to the capacity to rebuild in open sea that Neurath praises in his ship analogy (Cunha 2014).

Neurath claims that utopias are the experiments of social technology: as such, he says in an earlier text that "once we are clear about the fact that utopias as socialtechnology constructions can preserve us from many false steps and can make the mind flexible and free it from accidental notions, then we must demand that our

Principia 19(3): 363-377 (2015). 
schools should deal with social engineering constructions" (Neurath 1979 [1919], p.239). Therefore, by means of literary works and fanciful proposals, which take into account as many as possible aspects of a situation, social planners can discuss social inventions with the community. It is the public open debate about social arrangements, inventions, and proposals that serves as a test and helps to constitute the background of experience from which social science may derive predictions and be applied. In a debate, it is likely that some features of the Ballung emerge - important features that had not been regarded when the utopia was first proposed. In this context, Huxley's dystopia can be seen as a very powerful experiment: it shows the consequences of applying some unreflected proposals and, as debates are triggered, it lets us know how some social proposals are received.

And from a Neurathian point of view, we are able to see the mistake of the social engineers in Brave New World. They created a stable and unchangeable social order, from which humankind could not escape anymore; Huxley's engineers came up with solutions which were regarded as perfect, as if their answers to the problems of society were absolutely correct. Even though those solutions seemed perfect, Neurath's philosophy of science advises us not to consider them as such. They created the illusion of a dock, so to say, and pretended that they were no longer on the open sea. In Feyerabend's framework, they considered that their scientific theories, their standards of rationality, were perfect and ready to lead the whole of humankind towards an absolutely and eternally best situation. ${ }^{9}$

\section{Cartwright's Nomological Machines}

Hence, literary utopias are understood as imaginary experimental contexts for testing and articulating proposals in the social sciences, regarding many aspects of a social situation. Such contexts, therefore, are abstract arrangements in which scientific generalizations, or laws, work as planned, allowing the control of all the important features related to the theories involved, and enabling more generalizations to be obtained. Describing science as dealing with this kind of arrangement is not strange to philosophers of science, since it has been recognized for some decades that this is a fair description of the work scientists do with models, in spite of the many controversies regarding models in philosophy of science.

In Nancy Cartwright's proposal, as presented in The Dappled World, models are blueprints of nomological machines; in other words, models are sort of instructions or schemes for building, or accounting for, abstract arrangements, which, properly operated repeated times, exhibit the behavior described, or prescribed, by the scientific theories, laws, and generalizations (Cartwright 1999, p.50-9). ${ }^{10}$ In this outline, nomological machines are in a lower level of abstraction, they are closer to

Principia 19(3): 363-377 (2015). 
the experienced world than the models, which, in turn, are less abstract than the scientific laws. And by setting the domain of application of models to abstractions, to the nomological machines, it is possible to take into account that scientific theories, laws, and generalizations do not apply to reality directly, but only by means of the model's mediation. ${ }^{11}$ Scientific laws apply adequately only in the nomological machines, that is, they are true only if the conditions specified in the model are satisfied; in Cartwright's famous phrasing, "laws (...) hold only ceteris paribus", that is, "they hold only relative to the successful repeated operation of a nomological machine" (Cartwright 1999, p.49-50). In other words, laws work only if everything else remains stable, or if nothing else interferes, and such a condition can only be found in nomological machines, which are built for that very reason; experiments can only show the results expected by the theories in case there is an appropriate shielding, the isolation of the system (Cartwright 1999, p.60-3). The application of scientific theories to reality, according to Cartwright, is carried through by means of bridge principles, which hold in another kind of model, the interpretative models; these guide scientists, or engineers, in the adaptation of the theory to a situation in which other factors interfere, in which the ceteris paribus clause is not fully satisfied (Cartwright 1999, p.186-91).

The interesting aspect of Cartwright's account is that it creates degrees of abstraction between theory and experience: mathematical models, nomological machines, bridge principles, and interpretative models. L.H. Dutra acknowledges this aspect in his thorough survey of the model controversy in recent philosophy of science; he notices that in different fields of science, scientists often talk about models in reference to abstract structures that encompass more than just the mathematical and interpretative models, including also the nomological machine itself, and even the bridge principles (Dutra 2013, p.155-9). In his discussion, Dutra also identifies other kinds of models that appear in the pragmatic of scientific inquiry (Dutra 2013, chapter 9). He claims that mathematical models, such as those used in physics, cannot always be formulated in social science, ${ }^{12}$ because of the risk of oversimplifying social theories and situations. Nevertheless, abstract structures, such as nomological machines, commonly referred to as models, are present in social science (Dutra 2013, p.47).

The advantage of regarding theoretical interventions in experienced situations as mediated by such complex of abstract structures, besides the improvement of our understanding of the relations between theory and experience, is that it accounts explicitly for the plasticity of scientific knowledge. The constructions of science are thus characterized by its capacity of manipulating abstract arrangements, of creating new possibilities, from which to derive more generalizations, instead of sticking to the rigidness of scientific laws (Cartwright 1999, p.60-1). As Dutra points out, a great amount of scientific knowledge is obtained in manipulating models, particularly simulation models, to the extent that these promote changes in the theoretical 
models and ultimately in the scientific theories themselves. Moreover, simulations are less abstract than nomological machines, and, therefore, they indicate more concrete conditions for the application of theories (Dutra 2013, p.220-7).

This character of improving scientific knowledge by means of gathering new generalizations and enhancing old ones in the manipulation of different levels of abstract structures is assigned by Neurath to the scientific work with utopias, as we saw above. So, utopias can be understood as nomological machines, since they are abstract constructions in which social scientific theories work ideally, just as planned. Since utopias are devised from social scientific theories, or at least from beliefs as to how society works, or as to how society can be improved, they present the ceteris paribus clause for the laws, theories, beliefs, claims, etc., to work adequately, in a controlled manner. Utopias can also be understood as simulations, as thought experiments in which many theories are put to work together in conditions which resemble more closely the experienced situations. ${ }^{13}$

Nomological machines in Cartwright's account must be repeatedly operated in order that the behavior predicted by the theories shows up, and so that we can learn from them. She advances this character with reference to cases of quantum mechanics and economics, in which laws are probabilistic and demand an enormous number of experiments for some regularities to appear. I pointed out above that social science suffers with the impossibility of performing a large number of tests in order to gather regularities and devise generalizations; Neurath's view on utopias intends to work out this issue, for, as we have seen, he demands that proposals for social transformation must be broadly and thoroughly discussed. And, just as simulations and nomological machines have to be run many times for the application guidelines to emerge, utopias must likewise be discussed so that social engineers can learn ways for the democratic implementation of the social reforms proposed. Thus, utopias can also be understood as comprehending bridge principles and bridge models, which can be obtained in a social debate, as different groups come into contact with the utopia and react to it more or less regularly, enabling generalizations.

Following this perspective, it is possible to say that Brave New World presents a nomological machine, a model, in which Aldous Huxley put to work some proposals for social improvement that were popular at his time. ${ }^{14}$ And he seeks to show how, in spite of the good intentions, those proposals entail bad consequences. It is important to notice that Huxley's book shows not that the theories from which the proposals were derived were wrong, but that they were right, the theories work perfectly in the nomological machine. The unwanted consequences come from the fact that the social technologists who created that society did not consider all the aspects that form the Ballung, the irregular, indistinct, complex, and unique aggregate situation with which, according to Neurath, social science has to deal.

This takes us to the conclusion that social science presents a very particular kind

Principia 19(3): 363-377 (2015). 
of model: a nomological machine, which, like every machine as such, provides the ceteris paribus conditions the theories need in order to work. The laws and theories work in the model, as expected - they are confirmed, so to say, by the experiment. But they also exhibit unpredicted and undesirable consequences which may lead the community to abandon the theory, as if it was disconfirmed or falsified. Someone who, facing such dystopian prospects, feels inclined to reject any possibility of using science to plan society is rejecting well-confirmed theories because of some flaws terrible flaws, of course - in the models. But, in this case, the Neurathian answer is that we need more models, more nomological machines, and more discussion about them, for this is the way in which scientific knowledge is improved. ${ }^{15}$

\section{Concluding Remarks}

Social situations are complex compositions that have to be approached from many perspectives at the same time. Such a complexity imprints a character of uniqueness to social situations, so that social science cannot rely on past experiences to improve its plural approach. Models of social science, therefore, must take into account as many traits of the social situation as possible; and these models have to be discussed thoroughly to create a background of tests and generalizations. Neurath calls such models utopias, evoking the literary tradition of dealing with the diversity of intertwined aspects of a social situation. Utopias, or social-science models, can be regarded as nomological machines in the sense proposed by Cartwright, because they are arrangements which, by means of their repeated operation, provide a path of decreasing abstractness that leads from theories to experienced situations.

But attempts to create and apply utopias, that is to shape society using the models imagined by artists, scientists, and social technologists, seem to have the tendency to generate dystopias when applied, as Huxley fears. Indeed, M.L. Berneri points out, "when the 20th century has tried to carry out the utopian plans of the past it has failed miserably" (Berneri 1971 [1950], p.309). Such a failure, she claims, was due to the fact that many utopias of the 19th century were authoritarian: the writers of these utopias, Berneri says, in reference to the influential Étienne Cabet and Edward Bellamy, "loved authority, they were convinced that the 'people' had to be told what was good for them, they wanted order at any price, even that of bureaucracy, they hated individuality, they had narrow, 'inhuman' minds". (Berneri, 1971 [1950], p.310).

This is what seems to concern Feyerabend the most: that states, or big enterprises, or even crafty scientists, decide to shape society and individual lives according to their wish, vested with the so-called scientific authority. However, Berneri sees in mid-20th century literature a tendency of replacing this tradition of authoritarian

Principia 19(3): 363-377 (2015). 
utopias by a tendency towards dystopia. She notices that "for most writers of the 19th century, scientific discoveries and industrial development were going to increase automatically the happiness of humankind, but modern generations see the dangers as well as the advantages which 'progress' can bring" (Berneri 1971 [1950], p.310).

Hence, upon the realization of the fallibility of science, utopian literature changed towards a more cautionary stance, that of dystopian perspective. But society as a whole has not followed that movement: as pointed out by Feyerabend, scientism is endemic in Western society. At least in its advertised forms, science is not shown as prone to become a dystopia - one often gets the impression that with modern science everybody is happy all the time, just like in Huxley's Brave New World. The solution, according to Feyerabend, is that science becomes more plural, like the arts - or that we start to recognize that scientific progress depend on diversity. Neurath's call for creativity in social science goes in this very direction, as he wants scientists to take up the literary strategy of utopianism and to develop a plurality of standpoints.

In this context, H. G. Wells's utopias are relevant, because the communities are not presented as perfectly already-built, but constantly in the making. Wells presents utopias of societies that have the capacity of improving themselves through trial and error. The direction to be taken in those societies is to be decided in a constant open debate among the characters of the story. In such a debate, there is no sharp distinction between 'utopia' and 'dystopia'. Wells's utopias are ambiguous (Aldridge 1984; James, 2012). This constant debate is what I claim to be at the core of scientific utopianism, it is the repeated operation of the nomological machine. In this process, dystopias, the pessimistic models of social science, are just as important as utopias, for they instigate the debates, allowing new generalizations to come up, and leading our knowledge towards the concreteness of experienced problems.

Such debates, Feyerabend claims, can only be fully effective if the community is properly educated, that is, if the population is sufficiently informed to evaluate the alternatives of improvement. It is possible to notice that Feyerabend proposes some sort of utopia, in Neurath's sense: that of a free society in which people are wellinformed enough to perform their choices, and in which all traditions and standards are given the same opportunity to develop. Feyerabend does not believe that science might help prepare the citizens to live in such a free society - precisely because science has been institutionalized, it is conjoined to the state, it is used to keep people from reaching the maturity that is required to live in his utopia. ${ }^{16} \mathrm{He}$ is talking about the technocratic science, not the plural and fallibilist science present in Neurath's own utopia. Both utopias, Feyerabend's and Neurath's, can collaborate and can overcome the tendency of becoming dystopias. But this depends on our own work, on our ability to operate the nomological machine.

Principia 19(3): 363-377 (2015). 


\section{Acknowledgments}

This paper was developed with the support of a CAPES/PNPD grant. Preliminary versions were presented at the IX Principia Symposium (Florianópolis, Brazil, 2015) and at the 15th Congress of Logic, Methodology, and Philosophy of Science (Helsinki, Finland, 2015, supported by a CAPES/AEX travel grant). I thank the audience in those events for important remarks and debates; in particular: Alexander Linsbichler (University of Vienna, Austria); Valter A. Bezerra (University of São Paulo, Brazil); Caroline E. Murr (Federal University of Paraná, Brazil).

\section{References}

Aldridge, A. 1984. The scientific world view in dystopia. Ann Arbor: UMI.

Berneri, M. L. 1971 [1950]. A Journey Through Utopia. New York: Schocken.

Cartwright, N. 1983. How the Laws of Physics Lie. Oxford: Clarendon Press. . 1999. The Dappled World. Cambridge: Cambridge University Press.

Cartwright, N.; Cat, J.; Fleck, L.; Uebel, T. 1996. Otto Neurath: Philosophy Between Science and Politics. Cambridge: Cambridge University Press.

Cunha, I. F. 2014. Neurath e H. G. Wells: em direção a uma ciência social utópica. Gavagai 1(2): 40-53.

- 2015. Uma Discussão sobre a Unidade da Ciência: Neurath e a utopia da ciência unificada. Scientiae Studia 13(1): 97-122.

Dutra, L. H. 2013. Pragmática de Modelos. São Paulo: Loyola.

Feyerabend, P. 1982 [1978]. Science in a Free Society. London: Verso. 1993. Against Method. 3rd Edition. London: Verso.

Huxley, A. 2006 [1932]. Brave New World. New York: Harper Collins. 2006 [1958]. Brave New World Revisited. New York: Harper Collins.

James, S. 2012. Maps of Utopia. Oxford: Oxford University Press.

Nemeth, E. 1991. Neurath's Utopias: the Will to Hope. In: T. Uebel (ed.) Rediscovering the Forgotten Vienna Circle, p.284-92. Dordrecht: Kluwer.

Neurath, O. 1979 [1919]. Die Utopie als gesellschaftstechnische Konstruktion. In: Wissenschaftliche Weltauffassung, Sozialismus und logischer Empirismus, p.235-41. Frankfurt am Main: Suhrkamp.

- 2004 [1920-1]. A System of Socialization. In: Economic Writings: Selections 19041945, p.345-70. Dordrecht: Kluwer.

—_ 1981 [1930]. Bürgerlicher Marxismus. In: Gesammelte philosophische und methodologische Schriften, p.349-56. Wien: Hölder-Pichler-Tempsky.

- 1970 [1944]. Foundations of the Social Sciences. In: O. Neurath; R. Carnap; C. Morris (ed.) Foundations of the Unity of Science. Volume 2, p.1-51. Chicago: Chicago University Press.

Neurath, O.; Bohr, N.; Dewey, J.; Russell, B.; Carnap, R.; Morris, C. 1955 [1938]. Encyclopedia and Unified Science. In: O. Neurath; R. Carnap; C. Morris (ed.). International Encyclopedia of Unified Science. Volume 1, p.1-27. Chicago: Chicago University Press.

Russell, B. 2009 [1931]. The Scientific Outlook. New York: Routledge.

Principia 19(3): 363-377 (2015). 
Sánchez, S.L.R. 2006. Unidad de la Ciencia y Pluralismo Epistémico: Dos Proyectos Epistemológicos con Objetivos Políticos Comunes. Ludus Vitalis XIV(25): 75-94.

Wells, H. G. 2005 [1905]. A Modern Utopia. London: Penguin. 1923. Men Like Gods. Rockville: Wildside Press.

Yuann, J. J. 2007. A Naturalistic Approach to Scientific Methodology: A Comparative Study of O. Neurath and P. Feyerabend. In: C. M. Mi; R. L. Chen (eds.) Naturalized Epistemology and Philosophy of Science, p.171-196. Amsterdam: Rodopi.

\author{
IVAN FERREIRA DA CUNHA \\ State University of Maringá (UEM) \\ Brazil \\ clockwork.ivan@gmail.com
}

\title{
Notes
}

${ }^{1}$ Feyerabend argues against proposals that advance science as self-regulatory. He claims that self-regulation is not enough to prevent science's political misuse, and that citizens should be able to evaluate scientific efforts (Feyerabend 1993, p.251). I shall discuss that below.

${ }^{2}$ I use 'social science' in singular form to refer to such a plurality of sciences and approaches.

3 The German word 'Ballung' is translated in English as 'aggregate' by Neurath himself; he acknowledges, however, that this translation is complicate (Neurath 1970 [1944], p.18). A more adequate translation would perhaps be 'cluster', but Neurath does not mention it. I shall use here 'Ballung', except in direct quotations from Neurath's English texts, where 'aggregate' and 'aggregation' are used.

${ }^{4}$ This relates to one of Neurath's most famous proposals, physicalism, which is the construction of an empiricist universal jargon for science (Neurath 1970 [1944], p.1-19).

${ }^{5}$ This is coherent with Neurath's conception of the unity of science as a mosaic image, which is formed by irregular and uneven parts that constitute a whole by means of a general attitude or effort; likewise, science is composed of many irregular disciplines that do not fit perfectly together, but that may be united by their general empiricist attitude (Neurath et al. 1955 [1938], p.3-5; also see Cartwright et al. 1996, p.167-88).

${ }^{6}$ I use 'social engineering' and 'social technology' as synonyms in reference to the application of social science. The German word used by Neurath is 'Gesellschaftstechnik' (Neurath 1979 [1919]), which is usually translated as 'social engineering'; but it shares a radical with 'technology', which I prefer in order to avoid the negative charge that commonly accompanies 'social engineering'.

${ }^{7}$ See Cartwright et al. 1996, p.89-163 for a reconstruction and commentary of the many versions of the analogy.

8 This view was developed in opposition to the mainstream Marxism of Neurath's time, that of Karl Mannheim (see Neurath 1981 [1930], and also Neurath 2004 [1920-1]).

${ }^{9}$ When discussing the works of Neurath and Feyerabend, the problem of the unity of science commonly arises. The briefest look on their texts allows one to see that Neurath wanted to promote the unity of science, while Feyerabend was a champion of the disunity of science.

Principia 19(3): 363-377 (2015). 
Recent scholarship, however, shows a great deal of continuity between their philosophical projects. Both Neurath and Feyerabend attribute a central role to pluralism in their conceptions of science (see Sánchez 2006); moreover, both of them assume a naturalistic stance in epistemology (see Yuann 2007). Thus, the fundamental divergence between them lies not in the concept of science, but in their political stance: in the plurality of activities and efforts called 'science', Neurath sees a common attitude to be brought together and Feyerabend claims that such efforts and activities are better off detached. This is because Neurath is trying to protect a persecuted minority of scientifically-minded people in the 1930s and Feyerabend is fighting the abuse of scientific power. Neurath's view on utopias aims at creating a more humane science that can serve society, just like Feyerabend's considerations, but in another historical context. The difference in political orientation between them is understandable, since they "lived different historical moments, even though they come from a common philosophical tradition and their works are separated by just a few decades" (Sánchez 2006, p.89). I have discussed Neurath's position on the matter in contrast to disunity of science points of view in Cunha 2015.

${ }^{10}$ Cartwright discusses models in relation to laws, which she regards as high-level generalizations (Cartwright 1999, p.4; also see Cartwright 1983). But we can take her account in the broader, looser terms of theories.

${ }^{11}$ Cartwright advances a form of anti-realism regarding theories, but she insists that her arguments are sound even if a realist stance is assumed, as long as it is not a fundamentalist one (Cartwright 1999, p.24-8).

12 Dutra uses the expression 'human sciences' in reference to the "basic and intuitive idea" of the sciences which deal with "events that directly or indirectly depend on, or result from, human action" (Dutra 2013, p.305, footnote 1). This implies the same vagueness and plurality intended here with the expression 'social science'.

${ }^{13}$ Comparing fictional works to models is not properly novelty, since Cartwright herself compares models and nomological machines to fables (Cartwright 1999, chapter 2).

${ }^{14}$ Evidence that such proposals were under consideration in the early thirties is that Russell anticipated many of them, also calling for prudence regarding social engineering, in part III of The Scientific Outlook (Russell 2009 [1931]).

${ }^{15}$ It is important to remark that this conclusion conflicts neither with a Neurath-style unity nor with a Feyerabend-style disunity view of science. That is, in pointing out a particular feature in the procedures of social science, I am not proposing a fundamental difference in regard to natural science, granted that it is not the "method of modeling" that unifies science. In other words, I am making no claim regarding the unity or disunity of science. Also, this particular feature brings forward the possibility of open debate in social science and technology, a way to decentralize scientific power.

${ }^{16}$ Feyerabend believes that "citizen initiatives are the best and only school for free citizens we now have" (Feyerabend 1982 [1978], p.107). He elaborates on his conception of an ideal society piecemeal in other texts. Feyerabend's utopia of a free society is a theme for another paper.

Principia 19(3): 363-377 (2015). 